\title{
Live offspring from vitrified blastocysts derived from fresh and cryopreserved ovarian tissue grafts of adult mice
}

\author{
Xiaoqian Wang, Sally Catt, Mulyoto Pangestu and Peter Temple-Smith \\ Monash Institute of Medical Research, Centre of Reproduction and Development, Monash University, Clayton, \\ Victoria 3168, Australia \\ Correspondence should be addressed to P Temple-Smith; Email: peter.temple-smith@med.monash.edu.au
}

\begin{abstract}
Ovarian tissue cryopreservation and transplantation can be used to preserve fertility for cancer patients. In this study, we assessed the viability and function of ovarian tissue from adult mice that was cryopreserved by solid surface vitrification or traditional slow-cooling using various in vitro and in vivo techniques, including allotransplantation, in vitro oocyte maturation, embryo culture in vitro, blastocyst cryopreservation, embryo transfer, and development. The importance of cumulus cells for oocyte maturation, fertilization, and embryo development was investigated. Graft recovery, follicle survival, and oocyte retrieval was similar in control, vitrified, and slow-cooled groups. High rates of oocyte maturation, cleavage, and blastocyst formation were achieved, with no significant differences between the control, vitrified or slow-cooled ovarian tissue grafts. The presence of cumulus cells was important for oocyte maturation, fertilization, and subsequent development. Cumulus-oocyte complexes with no surrounding cumulus cells (N-COCs) or with an incomplete layer (P-COCs) had significantly lower rates of oocyte maturation and blastocyst formation than cumulus-oocyte complexes with at least one complete layer of cumulus cells (F-COCs; maturation rate: 63, 78 vs 94\%; blastocyst rate: 29 , 49 vs $80 \%$ ). Live births were achieved using vitrified blastocysts derived from oocytes taken from vitrified and slow-cooled ovarian tissue heterotypic allografts. Successful production of healthy offspring from these vitrified blastocysts suggests that this technique should be considered as a useful stage to pause in the assisted reproduction pathway. This provides an alternative protocol for restoring fertility and offering cancer patients a better indication of their chances of pregnancy and live birth.

Reproduction (2009) 138 527-535
\end{abstract}

\section{Introduction}

About 1 in 600 girls develop cancer within the first 15 years of life, but of these, more than $90 \%$ are cured using surgery and/or radiochemotherapy (Bath et al. 2002). However, these cancer patients are at risk of severely damaging or losing their ovarian function. Currently, the main options for them to preserve fertility are ovarian tissue, oocyte, or embryo cryopreservation. Many factors, such as female age, nature of disease, partner status, and moral or religious views, need to be considered when choosing the most suitable treatment (Donnez et al. 2006). Ovarian tissue cryopreservation has often been the only available option, especially for prepubertal girls and women who cannot delay their cancer treatment (Donnez et al. 2006). Improved ovarian tissue cryopreservation and transplantation protocols are needed to ensure the best outcomes for these patients (Donnez et al. 2006). Despite considerable interest, however, only five healthy babies have been born after cryopreservation and transplantation of human ovarian tissue (Donnez et al. 2004, Meirow et al. 2005, Demeestere et al. 2007, Andersen et al. 2008).
In animals, ovarian tissue cryopreservation and transplantation have been used for breeding, research, and conservation purposes in various species, including mouse, rats, rabbits, sheep, cats, wombats, and monkeys (Candy et al. 1995, 2000, Aubard et al. 1998, Wolvekamp et al. 2001, Salle et al. 2003, Almodin et al. 2004, Bosch et al. 2004). Slow-cooling, usually the method of choice for cryopreservation of ovarian tissue, is based on the principle of optimizing cooling rates to control injury from ice crystal formation, while minimizing chemical toxicity and osmotic stress from exposure to high concentrations of salts and solutes during freezing (Demirci et al. 2003).

Despite successes using slow-cooled cryopreserved ovarian tissue, vitrification has gained popularity. Vitrification is a process which aims to transform intraand extracellular fluids into a glass-like matrix without forming ice crystals. It is faster than slow-cooling and can be an effective method for cryopreserving ovarian tissue (Chen et al. 2006, Kagawa et al. 2007, Li et al. 2007). High concentrations of cryoprotectant and fast cooling rates are the most important elements in achieving vitrification. Different vitrification methods involving 
a variety of devices have been used for oocytes, embryos, or ovarian tissues, including electron microscope grids (Martino et al. 1996), open pulled straws (Vajta et al. 1998), nylon loops (Lane et al. 1999), solid surfaces (Al-aghbari \& Menino 2002), or dropping samples directly into liquid nitrogen ( $\mathrm{LN}_{2}$; Papis et al. 2000). Of these methods, solid surface vitrification has achieved good results with ovarian tissue. Using this method, tissue samples are normally placed in a very small volume of vitrification solution and cooled on a sterile metal surface to maximize the cooling rate, and minimize the potential for contamination of samples by $\mathrm{LN}_{2}$. Measures of survival of vitrified ovarian tissue after cryopreservation have included morphological examination (histology), viability assessment by viability staining or development in vitro or in vivo culture (Yeoman et al. 2005, Santos et al. 2007, Aerts et al. 2008). There are, however, limited data on the effects on the function of ovarian tissue vitrified using solid surface vitrification systems.

Cumulus cells are important for in vitro or in vivo oocyte maturation, fertilization, and subsequent embryo development. Removal of cumulus cells before in vitro maturation (IVM) procedures reduces the developmental potential of oocytes of many species, including mouse (Anderiesz \& Trounson 1995, Chang et al. 2005), rabbit (Tao et al. 2008), pig (Wongsrikeao et al. 2005), cow (Chian et al. 1994), and human (Johnson et al. 2008). Cumulus cells are of critical importance for the final stages of oocyte nuclear and cytoplasmic maturation (Goud et al. 1998, Moor et al. 1998), because compounds such as amino acids and pyruvate enter the oocytes through the cumulus cell foot processes (Gilchrist et al. 2004). With the decrease in the layers of cumulus cells surrounding rabbit oocytes, the maturation rates declined (Tao et al. 2008). The presence of cumulus cells and corona cells also significantly improves the developmental potential of matured oocytes post-fertilization (Anderiesz \& Trounson 1995).

In the mouse grafting model, healthy pups have been reported from F-COCs retrieved from fresh or cryopreserved ovarian grafts (Kagawa et al. 2007) while no attention has been drawn to those N-COCs or P-COCs. However, such selective criteria cannot always be used clinically, because the main aim is to maximize the number of matured oocytes for fertilization in vitro. In clinical settings, it is also normal to remove cumulus cells in order to assess their maturation status and for ICSI (Chin \& Chye 2004). This study will investigate the developmental potential of oocytes (with or without cumulus cells enclosed) derived from fresh and cryopreserved ovarian grafts using a mouse model and the effect on live birth rate of vitrifying and storing blastocyst prior to embryo transfer.

In this study, a solid surface vitrification technique was compared with a traditional slow-cooling method. The cryopreserved adult mouse ovarian tissues were transplanted into severe combined immune-deficient (SCID) mice. Fresh mouse ovarian tissues were used as controls. The aims were: 1) to evaluate two cryopreservation strategies for mouse ovarian tissues, by determining the subsequent graft development and survival, and the viability of the oocytes recovered from these grafts, 2) to test the need for cumulus cells to mature and fertilize oocytes derived from unfrozen and cryopreserved ovarian grafts, and 3) to assess the effect on live birth rate of vitrifying and storing pre-implantation embryos derived from cryopreserved ovarian tissues prior to embryo transfer.

\section{Results}

\section{Graft survival and oocyte recovery}

Subcapsular grafts of ovarian tissue were successfully retrieved from the kidney after transplantation in all treatment groups. Recovery and survival rates for the vitrified and slow-cooled ovarian grafts were similar to those of the fresh controls (Table 1).

A total of 308, 303, and 267 oocytes were collected from vitrified, slow-cooled, and fresh grafts respectively. In fresh controls, $46 \%$ of the oocytes recovered were cumulus-enclosed oocytes, and the remainders were either partially surrounded by cumulus cells or were cumulus-free. Similar proportions were found in recovered oocytes from the vitrification and slowcooling treatment groups. The mean number of oocytes retrieved per survived quarter-ovarian graft in the vitrification group $(3.56 \pm 1.29)$ was not significantly different from the slow-cooling $(4.42 \pm 0.78)$ or fresh controls (3.66 \pm 0.61 ; Table 1$)$.

\section{Morphological examination}

Most of the fresh or cryopreserved quarter-ovarian grafts were successfully recovered and contained growing follicles after 12 days transplantation under the kidney capsule in SCID mice. Antral follicles were obvious and easily identified, and revascularization of the grafted tissue could also be seen. Histological examination

Table 1 Comparison of the number of grafts recovered and survived and oocytes retrieved from fresh, vitrified, and slow-cooled ovarian grafts after 12 days transplantation under the kidney capsule.

\begin{tabular}{|c|c|c|c|c|}
\hline $\begin{array}{l}\text { Treatment } \\
\text { group }^{\mathrm{a}}\end{array}$ & $\begin{array}{l}\text { Number of } \\
\text { grafts } \\
\text { recovered/ } \\
\text { number } \\
\text { grafted }\end{array}$ & $\begin{array}{l}\text { Number of } \\
\text { grafts } \\
\text { survived/ } \\
\text { number } \\
\text { recovered }\end{array}$ & $\begin{array}{c}\text { Total } \\
\text { number of } \\
\text { oocytes } \\
\text { collected }\end{array}$ & $\begin{array}{c}\text { Number of } \\
\text { oocytes } \\
\text { retrieved/ } \\
\text { survived } \\
\text { graft }\end{array}$ \\
\hline Fresh grafts & 84/88 (95\%) & $74 / 84(88 \%)$ & 267 & $3.66 \pm 0.61$ \\
\hline Vitrified grafts & $98 / 104(94 \%)$ & $86 / 98(83 \%)$ & 308 & $3.56 \pm 1.29$ \\
\hline $\begin{array}{l}\text { Slow-cooled } \\
\text { grafts }\end{array}$ & $72 / 80(90 \%)$ & $69 / 72(96 \%)$ & 303 & $4.42 \pm 0.78$ \\
\hline
\end{tabular}

${ }^{a}$ No significant difference was observed in any of these parameters between the two treatment groups and the fresh control grafts. 

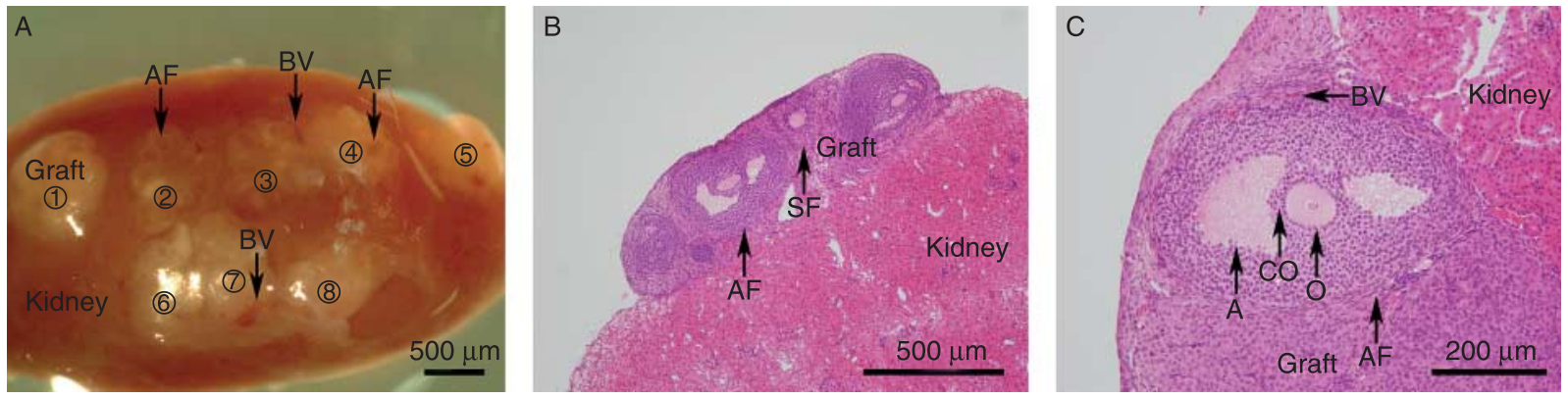

Figure 1 The morphology of grafts on the kidney of SCID mice after 12 days transplantation. (A) Eight pieces of slow-cooled grafts are visible with obvious antral follicles. Different number indicates the position of each graft. (B) Histological section of fresh grafts with multiple follicle growth. (C) Higher magnification of histological section showing antral follicle formation in a vitrified graft. A, antrum; $\mathrm{AF}$, antral follicle; $\mathrm{BV}$, blood vessel; CO, cumulus oophorus; O, oocyte; and SF, secondary follicle.

demonstrated that multiple follicles were developed after 12 days transplantation and antral follicles were easily distinguished by antrum cavity formation adjacent to full-sized oocytes (Fig. 1).

\section{Oocyte maturation, fertilization, and embryo development}

A total of 308 oocytes with or without cumulus cells were retrieved from 86 vitrified ovarian grafts and $77 \%$ matured in vitro. Of these, $73 \%$ cleaved to 2-cell embryos after IVF, and $62 \%$ of the 2-cell embryos developed to blastocysts. A total of 69 slow-cooled grafts produced 303 oocytes, of which $84 \%$ matured in vitro. After insemination, $80 \%$ of the matured oocytes cleaved to form 2-cell embryos, and $63 \%$ of these developed to blastocysts. From the 74 fresh control grafts, a total of 267 oocytes were recovered, $83 \%$ were matured in vitro, resulting in $76 \% 2$-cell embryos, of which $58 \%$ developed to blastocysts. No significant difference was found in the incidence of oocyte maturation, embryo cleavage, and blastocyst development between control and different cryopreservation treatment groups (Fig. 2).

The effect of cumulus cells on oocyte maturation, early cleavage, and subsequent embryo development was also examined (Fig. 2). A total of 354 F-COCs, 269 P-COCs, and $255 \mathrm{~N}$-COCs were retrieved from the different treatment groups. F-COCs had a significantly higher maturation rate $(94 \%)$ when compared with P-COCs $(78 \%, P<0.01)$ and $\mathrm{N}-\mathrm{COCs}(63 \%, P<0.001)$. No statistical difference was found in cleavage rate between F-COCs (83\%), P-COCs (67\%), and N-COCs (76\%). With embryos cultured until day 4 or 5, F-COCs ( $80 \%$ ) yielded a significantly higher percentage of blastocysts than that of P-COCs $(49 \%, P<0.01)$ and N-COCs $(29 \%, P<0.001)$.

\section{Blastocyst recovery and viability after cryopreservation and embryo transfer}

All blastocysts (graded 1 or 2) developing at day 4 or day 5 from the control and treatment groups were vitrified and stored in $\mathrm{LN}_{2}$ for 1-2 weeks before warming.
After $2 \mathrm{~h}$ post-thaw culture in blastocyst medium, a total of 80 vitrified blastocysts derived from F-COCs from the fresh or cryopreserved groups that showed signs of re-expansion were transferred into five surrogate recipients (15-16 embryos/recipient). All recipients became pregnant. Eight (25\%; 4 male and 4 female) healthy pups were born from 32 vitrified-warmed blastocysts derived from vitrified grafts, and four (12.5\%; 2 male and 2 female) pups were born from the same number of vitrified-warmed blastocysts from slowcooled grafts. In the fresh grafting controls, five male pups $(31 \%)$ were born after transferring 16 vitrifiedwarmed blastocysts (Table 2). All the pups developed normally to weaning age. Four pups (2 from vitrification and two from slow-cooling group) were mated with their siblings and all produced normal-sized healthy offspring.

\section{Discussion}

When attempting to preserve the fertility of cancer patients, ovarian tissue cryopreservation has many potential merits over embryo or oocyte cryopreservation. The ovary harbors numerous immature oocytes that can maximize the production of gametes; and most of those oocytes are quiescent and have relatively low metabolic rates, which make them more tolerant to cryopreservation injury, and most important is that no ovarian stimulation is required so that patients do not have to delay their cancer treatment (Gosden et al. 2002, Amorim et al. 2003). However, there is still contention about which cryopreservation methods are the most suitable for ovarian tissue. This research examined whether the solid surface vitrification procedure produced different results from the standard slow freezing protocols currently being used clinically and whether vitrification of blastocysts produced from oocytes retrieved from ovarian tissue allografts can be used successfully to provide a pause in the procedure prior to embryo transfer. Our data show that the viability and function of ovarian tissue cryopreserved using the solid surface vitrification method are similar to those in slow-cooled tissue after transplanting 

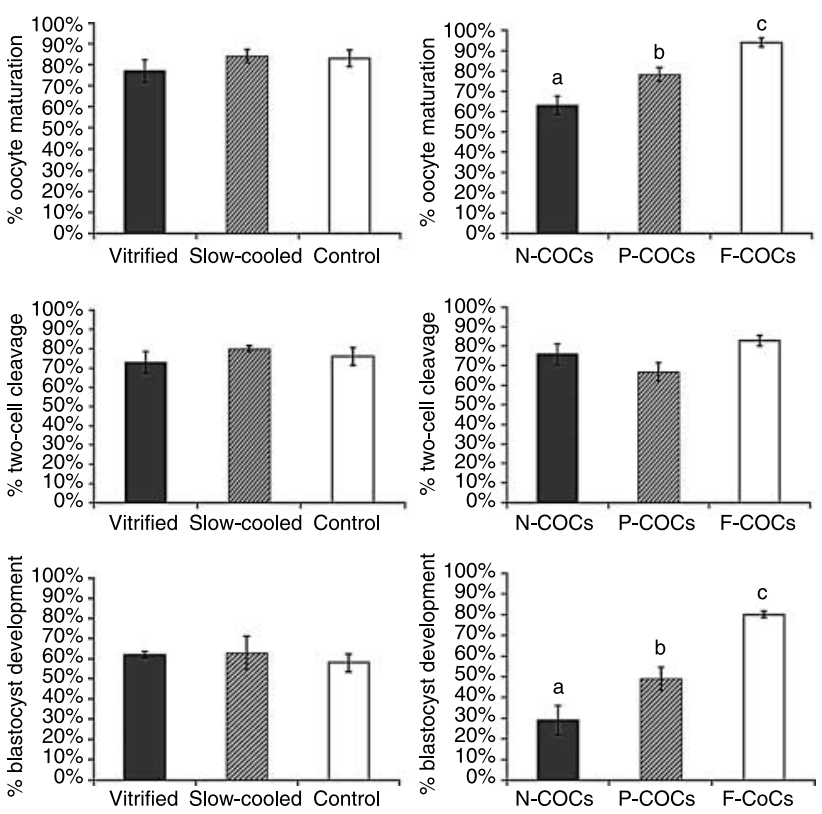

Figure 2 Developmental competence of oocytes collected from fresh and cryopreserved ovarian grafts with different oocyte classification. Note: oocyte maturation rate, total number of oocyte matured/total number of immature oocytes collected; cleavage rate, total number of 2-cell embryos/total number of oocytes matured; blastocyst rate, total number of blastocysts/total number of 2-cell embryos. Mean values with different superscript letters $(a, b, c)$ are significantly different from each other $(P<0.05)$. N-COCs, oocytes with no surrounding cumulus cells; P-COCs, oocytes with partial cumulus mass; F-COCs, oocytes with at least one complete layer of cumulus cells.

in vivo suggesting that it can be an efficient and cost effective alternative to slow-cooling.

In this study, SCID mice were used as 'living incubators' for the fresh and cryopreserved adult mouse ovarian tissue allografts to observe oocyte development and maturation. Some successes have been reported by maturing oocytes in vitro (Liu et al. 2001) or in vivo (Snow et al. 2004) from cryopreserved ovaries from immature mice. However, the success for mature adult mice is still limited (Lee et al. 2005, Kagawa et al. 2007). The ovaries of adult mice have more collagen fiber compared with those of immature mice, making them relatively harder and difficult to revascularize quickly after transplantation (Kagawa et al. 2007),

Table 2 Number of pups born after transferring vitrified-thawed blastocysts from fresh or cryopreserved mouse ovarian grafts.

\begin{tabular}{lccc}
\hline Treatment group & $\begin{array}{c}\text { Number of } \\
\text { recipients }\end{array}$ & $\begin{array}{c}\text { Number of } \\
\text { blastocysts } \\
\text { transferred }\end{array}$ & $\begin{array}{c}\text { Number of } \\
\text { pups born/ } \\
\text { recipient }(\%)\end{array}$ \\
\hline Vitrified grafts & 2 & 32 & $2 / 16(12.5 \%)$ \\
Slow-cooled grafts & 2 & 32 & $6 / 16(37.5 \%)$ \\
& 1 & 16 & $2 / 16(12.5 \%)$ \\
Fresh grafts & 1 & & $5 / 16(12.5 \%)$
\end{tabular}

No significant difference $(P<0.05)$ was found within or between each treatment group. fibrous connective tissue might also affect the permeability of cryoprotectant, compromising the tissue recovery after cryopreservation procedures.

Therefore, it is important to choose the 'right' size of tissue for cryopreservation and transplantation. A previous study by Kim et al. (2002) found that tissue ischemia and fibrosis formation is obvious after transplanting large piece of ovarian grafts $(5 \mathrm{~mm}$ in size). Kagawa et al. (2007) suggested minimizing the size of mouse ovarian graft $(0.2-0.3 \mathrm{~mm})$ to accelerate revascularization speed, based on the texture difference between mature and immature mice ovary. Here, we cut the adult mouse ovary into medium size pieces $(1-1.5 \mathrm{~mm} /$ piece) and transplanted these under the kidney capsule of SCID mice. Histological examination showed numerous follicles with full size oocytes developing in revascularized grafts. Our results showed that mouse ovarian grafts that were 5-10 times larger than the minimum size recommended by Kagawa et al. (2007), were easier to handle than smaller pieces, and showed very good recovery, vascularization, and survival after heterotypic allografting. These grafts also produced large numbers of oocytes that were competent for use in IVM and IVF tests.

Ovarian tissue contains multicellular and heterogeneous components (Gosden et al. 2002). To protect different types of follicles and support cells from cryoinjury, a subtle balance is needed between the choice of cryoprotectants and carriers, concentrations and equilibration periods for cryoprotectants, and cooling and warming rates. The cryologic solid surface vitrification method was found to be a simple and convenient freezing method for cryopreservation of ovarian tissue in this study, and has also been used successfully to cryopreserve embryos and oocytes with a high post-thaw survival rate in other species (Fry et al. 2005, Beebe et al. 2006, Costigan et al. 2006). Aerts et al. (2008) used the cryologic solid surface vitrification method to cryopreserve mouse ovarian tissue and assessed the survival of thawed tissues using histological examination and viability staining 7 days after heterotypic allografting in the kidney. Their results showed the fraction of intermediary and primary follicles significantly increased in both vitrified and slow-cooled grafts, but slow-cooled tissues yielded a significantly higher proportion of further developed follicles, including secondary and antral follicles, suggesting that the solid surface method may have inhibited follicle growth.

By contrast, in this study, follicle survival and development in ovarian tissue vitrified using the cryologic solid surface vitrification method was comparable with the traditional slow-cooling method. Our results were superior, in terms of graft recovery and the proportion of oocytes maturation in F-COCs group, to those reported by Kagawa et al. (2007) who vitrified mouse ovarian cubes using a cryotop vitrification method. The cleavage rate in our study was also higher 
than that of Kagawa et al. (2007) (94/110, 85\% vs 57/76, $75 \%)$. It is difficult to compare the embryo developmental competence between these two studies as Kagawa et al. (2007) transferred the embryos at early cleavage stage, whereas we further cultured all the embryos to blastocyst stage. Out of 94, 76 (81\%) cleaved embryos developed to blastocysts originating from F-COCs from vitrified grafts indicating high embryo developmental competency. This increased competency was also indicated in our embryo transfer study, even though our embryos were vitrified prior to transfer, the live-pup birth rate from fresh $(5 / 16,31 \%)$ and vitrified grafts $(8 / 32,25 \%)$ were similar to Kagawa et al. (2007) (18\% from vitrified grafts, $26 \%$ from fresh grafts). This relatively low success rate is likely to reflect the combined effect of transplantation, IVM, IVF, and in vitro culture to the blastocyst stage since we achieve a live-pup birth rate of $71 \%(22 / 31)$ when we transfer vitrified-warmed blastocysts derived from in vivo fertilized oocytes cultured in vitro from the 2-cell stage (X Wang, unpublished observation).

Although there was no difference in oocyte maturation, fertilization, and subsequent embryo development between vitrification and slow cooling cryopreservation methods, significant differences were found between oocyte types (with or without cumulus cells). The F-COCs had significantly higher maturation, cleavage, and blastocyst rates than $\mathrm{N}$-COCs or P-COCs confirming other studies that matured mouse oocytes in vitro with cumulus cells (Anderiesz \& Trounson 1995) or without cumulus cells (Chin \& Chye 2004, Chang et al. 2005). However, even oocytes recovered without cumulus cells showed some degree of developmental competence (29\% blastocyst rate). In this study, only blastocysts from F-COCs originating from fresh or cryopreserved ovarian grafts were used for embryo transfer. It will be interesting to investigate if those blastocysts developed from P-COCs or N-COCs have similar implantation competence as F-COCs. The lack of developmental competence of $\mathrm{N}$-COCs or P-COCs are most probably associated with ooplasm defects because transfer of pronuclei from those oocytes into the enucleated cytoplast of in vivo matured oocytes significantly increased the number of embryos that developed to blastocysts (Chang et al. 2005). Co-culture of N-COCs or P-COCs with granulosa cells (Dandekar et al. 1991, Yamazaki et al. 2001) or addition of serum (Kito \& Bavister 1997, Yamazaki et al. 2001) may enhance their meiotic maturation and subsequent developmental potential in vitro.

Embryo cryopreservation is a well-established protocol and many IVF clinics now reduce their multiple pregnancy rate by performing single embryo transfers and cryopreserving excess embryos (Youssry et al. 2008). In humans, combination of oocyte and early stage of embryo cryopreservation have been used to produce healthy babies (Levi Setti et al. 2005, Chen et al. 2008).
In this study, we have used two different cryopreservation steps - ovarian tissue and blastocyst cryopreservation to re-establish fertility after ovariectomy. We chose to cryopreserve all the embryos derived from fresh and cryopreserved ovarian grafts at the blastocyst stage, because blastocysts are pre-implantation embryos that have passed through most of the genomic activation period and have a relatively high developmental potential (Ménézo 2004). The live births achieved in this study from vitrified blastocysts transferred to recipient mice are the first to be reported using the cryologic solid surface vitrification method. Our result emphasizes the importance of cryobiology in reproductive science and the potential advantages of combining ovarian tissue cryopreservation and embryo cryopreservation in preserving fertility of women undergoing treatment for cancer.

In conclusion, adult mouse ovarian tissues can be successfully cryopreserved by the cryologic solid surface vitrification method and successfully transplanted under the mouse kidney capsule. The existing IVM system has been successfully used to mature oocytes derived from cryopreserved grafts. Oocytes from these grafts had high oocyte maturation, cleavage, and blastocysts rates in both the vitrification and slow-cooling groups. The presence of cumulus cells correlated closely with the capacity for oocyte maturation and fertilization in vitro. The combination of ovarian tissue cryopreservation and a standard blastocyst freezing protocol can yield offspring at a high rate. Such findings are important to understand the usefulness of cryobiology in assisted reproduction and to consider their use in clinical treatments.

\section{Materials and Methods}

All the chemicals and reagents used for this study were purchased from Sigma Chemical (Sigma) unless otherwise stated.

\section{Animals}

The study was approved by the Monash Medical Centre Animal Ethics Committee (approval number A2008/15). Six-to-sevenweeks-old F1 female hybrid $(\mathrm{C} 57 \mathrm{BL} \times \mathrm{CBA})$ mice were used as ovarian tissue donors $(n=40)$, and $8-10$-weeks-old SCID female mice were used as graft recipients $(n=20)$. Eightweek-old F1 hybrid (C57BL $\times$ CBA; $n=5)$ female hybrids were mated with proven vasectomized $\mathrm{F} 1$ hybrid $(\mathrm{C} 57 \mathrm{BL} \times \mathrm{CBA})$ males and used as pseudo-pregnant embryo transfer recipients. Twelve-week-old F1 male hybrids (C57BL $\times$ CBA) were used as sperm donors for IVF. All mice were obtained from Monash University Animal Services and housed in specific pathogenfree conditions with a relative humidity of $30-60 \%$, a temperature range from 21 to $24{ }^{\circ} \mathrm{C}$ and a $12 \mathrm{~h}$ light: $12 \mathrm{~h}$ darkness light cycle. All mice had free access to sterile food and water. 


\section{Ovarian tissue collection}

Female donor mice were killed by cervical dislocation, and ovaries were collected and placed into HEPES-buffered KSOM handling medium (KSOM HM; Summers et al. 1995) supplemented with $0.5 \% \mathrm{w} / \mathrm{v}$ BSA. Each ovary was then cut into quarters using a razor blade (ProSciTech, Brisbane, QLD, Australia) and transplanted under the kidney capsule of SCID mice either immediately (controls) or after cryopreservation.

\section{Ovarian tissue cryopreservation}

\section{Vitrification}

For vitrification, the tissue fragments were initially equilibrated in $\mathrm{KSOM} \mathrm{HM}$ containing $10 \% \mathrm{v} / \mathrm{v}$ ethylene glycol (EG) and $10 \% \mathrm{v} / \mathrm{v}$ DMSO for $20 \mathrm{~min}$ at room temperature (RT) and then transferred to vitrification solution containing $17 \% \mathrm{v} / \mathrm{v}$ EG and $17 \% \mathrm{v} / \mathrm{v}$ DMSO and $0.75 \mathrm{M}$ sucrose in KSOM HM for $3 \mathrm{~min}$. Each ovarian tissue fragment was then transferred with a minimum volume $(1-3 \mu \mathrm{l})$ of the vitrification solution on to the hook-end of a plastic Fiberplug and vitrified by contacting the hook-end of the Fiberplug with the surface of metal block (CVM kit, Cryologic, Melbourne, VIC, Australia) pre-cooled by practical immersion into $\mathrm{LN}_{2}$ (Fig. 3). Fiberplugs were then inserted into corresponding storage straws and plunged into pre-cooled goblets for storage in $\mathrm{LN}_{2}$. To warm the ovarian tissue fragments, Fiberplugs were removed from the storage straw and immersed in 0.5 M sucrose in KSOM HM for 5 min at $37^{\circ} \mathrm{C}$, and then the tissue fragments were washed through stepwise solutions in $\operatorname{KSOM~HM}(0.25,0.125,0 \mathrm{M}$ sucrose, 5 min each). After washing and prior to grafting, the tissues were held in $\mathrm{KSOM} \mathrm{HM}$ at $37^{\circ} \mathrm{C}$.

\section{Slow-cooling}

For slow-cooling, we used the method of Snow et al. (2004) with minor modifications. Briefly, up to eight ovarian fragments were placed into the slow-cooling solution containing $10 \% \mathrm{v} / \mathrm{v}$ DMSO and 0.1 M sucrose and loaded into $0.5 \mathrm{ml}$ plastic straws (IMV, L'Aigle, France). Straws were sealed with polyvinyl alcohol powder and after equilibration for $10 \mathrm{~min}$ at RT, placed in a programmable freezer (Freeze Control CL8800i, Cryologic) and cooled at $2{ }^{\circ} \mathrm{C} / \mathrm{min}$ from RT to $-7{ }^{\circ} \mathrm{C}$. Straws were held at $-7^{\circ} \mathrm{C}$ for $10 \mathrm{~min}$ at which stage the straws were seeded (Fig. 3), and then taken down to $-40^{\circ} \mathrm{C}$ at a rate of $0.3^{\circ} \mathrm{C} / \mathrm{min}$. Straws were then removed from the cryochamber and plunged directly into $\mathrm{LN}_{2}$ and stored. For thawing, each straw was held
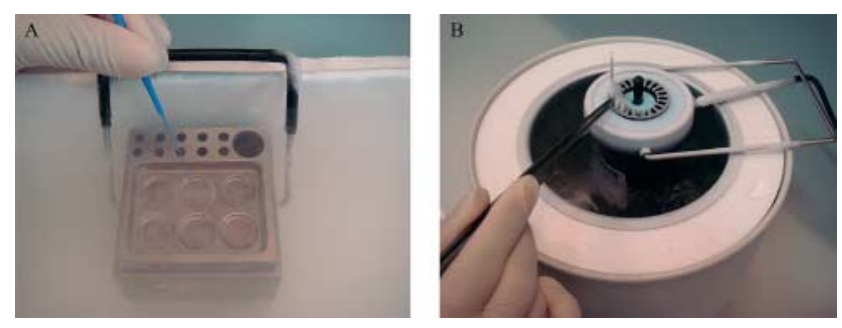

Figure 3 Vitrification and slow cooling equipment. (A) Touching a Fibreplug to cold metal block during vitrification. (B) Manual seeding during slow-cooling. in $\mathrm{LN}_{2}$ vapor for $10 \mathrm{~s}$, placed at RT for $30 \mathrm{~s}$, and then immersed in a $37^{\circ} \mathrm{C}$ water bath for $20 \mathrm{~s}$. The end of each straw was cut using sterile scissors and the thawed ovarian fragments were expelled into $30 \mathrm{~mm}$ petri dish (Becton Dickinson, Franklin Lakes, NJ, USA) containing 0.5 M sucrose solution in KSOM $\mathrm{HM}$ for $5 \mathrm{~min}$ at RT and then subsequently moved to 0.25 , 0.125 , and $0 \mathrm{M}$ sucrose in KSOM HM for 5 min each. All the thawed tissues were kept in KSOM HM before grafting.

\section{Ovariectomy and transplantation}

Ovarian grafting was performed using a standard procedure (Cox et al. 2000, Snow et al. 2002). In brief, tissue transplant recipients (8-10-week-old female SCID mice) were anesthetized (Avertin $(20 \mathrm{mg} / \mathrm{ml} \mathrm{2,} \mathrm{2,} \mathrm{2-tribromoethanol} \mathrm{and} 2 \% \mathrm{v} / \mathrm{v}$ tert-amyl alcohol), $0.4 \mathrm{mg} / \mathrm{g}$ body weight, i.p). The dorsal skin over the flank was sterilized using $70 \% \mathrm{v} / \mathrm{v}$ ethanol and a $1.5 \mathrm{~cm}$ dorsal incision was made through the skin. The skin was separated from the underlying tissue to allow access on each side to the lateral body wall about $0.5 \mathrm{~cm}$ from the mid-line to the right or left. A $0.5 \mathrm{~cm}$ incision was made through the abdominal wall to expose the ovarian fat pad and bilateral ovariectomy was performed (Nagy et al. 2003). Eight ovarian fragments from each donor mouse selected from one of the three groups (fresh controls, vitrified, or slow-cooled) were inserted under the capsule of one kidney in the recipient. A similar number of ovarian fragments from a donor taken from one of the two remaining groups were inserted under the capsule of the contralateral kidney. Fresh ovarian fragments (controls) were transplanted within $15 \mathrm{~min}$ of removal from the abdominal cavity and cryopreserved ovarian fragments were transplanted within $15 \mathrm{~min}$ of thawing. Each kidney was returned to the body cavity, the body wall incisions closed with 5/0 suture (Ethicon, Somerville, NJ, USA) and the skin incision closed with Michel clips (Clay Adams, Sparks, MD, USA). Prior to the mice returning to consciousness, analgesic (Carprofen (Rimadyl, Dundee, UK), $5 \mathrm{mg} / \mathrm{kg}$, i.p.) was used to provide post-surgery pain relief.

\section{Oocyte collection and IVM}

Ten days after transplantation, recipients were injected i.p. with 7.5 IU pregnant mares serum gonadotrophin (Folligon; Intervet, Boxmeer, The Netherlands) and killed by cervical dislocation $48 \mathrm{~h}$ later. Ovarian grafts were either removed and fixed in situ under the kidney capsule for histological assessment, or excised and placed in $\mathrm{KSOM} \mathrm{HM}$ at $37^{\circ} \mathrm{C}$ for oocyte collection and maturation. Antral follicles from the fresh and cryopreserved grafts were punctured with 26 gauge needles to release the oocytes. To assess the effects of cumulus cells on oocytes maturation, fertilization and subsequential embryo development, the retrieved oocytes were separated into one of the following groups: F-COCs; P-COCs; and N-COCs. For oocyte maturation, a modification of the method of Cortvrindt et al. (1996) was used. The maturation medium was Alpha-Minimum Essential Medium (Invitrogen), supplemented with 5\% v/v heatinactivated FCS (Invitrogen), $5 \mu \mathrm{g} / \mathrm{ml}$ insulin, $5 \mu \mathrm{g} / \mathrm{ml}$ transferrin and $5 \mathrm{ng} / \mathrm{ml}$ selenium, $50 \mathrm{mIU} / \mathrm{ml}$ penicillin and $50 \mu \mathrm{g} / \mathrm{ml}$ streptomycin, $2 \mu \mathrm{g} / \mathrm{ml} \mathrm{FSH}$ (Folltropin-V ; BioNiche, Belleville, 
ON, Canada), $1.5 \mathrm{IU} / \mathrm{ml}$ hCG (Chorulon, Intervet) and $5 \mathrm{ng} / \mathrm{ml}$ recombinant human epidermal growth factor (Invitrogen). Up to two oocytes were cultured in $20 \mu \mathrm{l}$ drops in $60 \mathrm{~mm}$ Falcon dishes under mineral oil at $37{ }^{\circ} \mathrm{C}$ in $100 \%$ humidity and $5 \%$ $\mathrm{CO}_{2}$ in air for $18 \mathrm{~h}$.

\section{IVF and embryo culture}

Male F1 $(\mathrm{C} 57 \mathrm{BL} \times \mathrm{CBA})$ mice were killed by cervical dislocation and the caudae epididymides were dissected, halved, and placed in $1 \mathrm{ml}$ pre-equilibrated modified Tyrodes solution (MT6; Fraser 1984) in a $5 \mathrm{ml}$ Falcon tube (BD Biosciences, San Jose, CA, USA) to recover sperm samples. After $30 \mathrm{~min}$ incubation at $37^{\circ} \mathrm{C}$ in $100 \%$ humidity and $5 \% \mathrm{CO}_{2}$ in air, the supernatant containing high number of motile sperms was harvested and the sperm concentration and motility assessed before insemination. Insemination dishes were prepared the day before with $100 \mu$ l MT6 medium droplets covered with a layer of mineral oil in $60 \mathrm{~mm}$ Falcon dishes and allowed to equilibrate at $37{ }^{\circ} \mathrm{C}$ in $100 \%$ humidity and $5 \% \mathrm{CO}_{2}$ in air for at least $12 \mathrm{~h}$. After maturation, oocytes with or without cumulus from different treatment groups were inseminated in different dishes with $1 \times 10^{6}$ spermatozoa/ml for $2-4 \mathrm{~h}$. At the end of this period when the cumulus had been dispersed, the maturation status of each oocyte was scored as follows: germinal vesicle visible (GV); GV absent but no polar body recognizable (GVBD/ metaphase I (MI)); or a polar body presents (MII). All MII oocytes were washed and cultured in Sydney IVF Cleavage Medium (Cook Australia, Brisbane, QLD, Australia) for 2 days and transferred to Sydney IVF Blastocyst Medium (Cook Australia) from day 3 until day 5 at $37{ }^{\circ} \mathrm{C}, 6 \% \mathrm{CO}_{2}, 5 \% \mathrm{O}_{2}$ atmosphere.

\section{Blastocyst vitrification and warming}

All day 4 or day 5 blastocysts were graded using the following criteria: Grade 1, blastocyst with tightly packed inner cell mass and trophectoderm with many cells; Grade 2, blastocyst with loosely packed inner cell mass and trophectoderm with few cells; and Grade 3, blastocyst with significant vacuoles, fragments, and/or signs of degeneration. Only Grade 1 or 2 blastocysts were vitrified and all the other embryos were discarded. For vitrification, blastocysts were initially equilibrated in KSOM HM containing 10\% v/v EG and 10\% v/v DMSO for $3 \mathrm{~min}$ at $37{ }^{\circ} \mathrm{C}$ and then transferred to vitrification solution in KSOM HM containing $17 \%$ v/v EG and $17 \%$ v/v DMSO and $0.75 \mathrm{M}$ sucrose for $30 \mathrm{~s}$ at $37^{\circ} \mathrm{C}$. Each blastocyst was then placed in $2 \mu \mathrm{l}$ vitrification solution onto the hook end of the plastic Fiberplug, and vitrified by contacting the hook end of Fiberplug with the surface of metal alloy block pre-cooled by immersion into $\mathrm{LN}_{2}$. Fiberplugs were subsequently placed into corresponding storage straws and then plunged into $\mathrm{LN}_{2}$ in precooled goblets for storage. To thaw vitrified blastocysts, Fiberplugs were removed from the straw and submerged immediately into $0.3 \mathrm{M}$ sucrose solution at $37^{\circ} \mathrm{C}$. Blastocysts were then quickly retrieved and transferred through a series of three solutions $(0.25,0.15,0 \mathrm{M}$ sucrose $)$ for $5 \mathrm{~min}$ each at $37^{\circ} \mathrm{C}$. All the warmed blastocysts were cultured in Sydney IVF blastocyst medium at $37^{\circ} \mathrm{C}$ in a $6 \% \mathrm{CO}_{2}, 5 \% \mathrm{O}_{2}$ atmosphere. Two hours later all the blastocysts were scored and transferred.

\section{Embryo transfer}

Five F1 $(\mathrm{C} 57 \mathrm{BL} \times \mathrm{CBA})$ female mice (8-weeks-old) were used as embryo transfer recipients after mating with vasectomized F1 males from the same strain. The females were checked for the evidence of vaginal plugs after mating. Recovered blastocysts from different treatment groups were transferred into the uterus of day 2.5 pseudo-pregnant recipients using the method described by Nagy et al. (2003). Briefly, the recipients were anesthetized as described above. A $1 \mathrm{~cm}$ skin incision was made in the dorsal midline at the level of the last rib, the skin was separated from the underlying tissues using blunt dissection to the left and right until the ovarian fat pad was visible under the abdominal wall on each side. A $0.5 \mathrm{~cm}$ incision was made in the abdominal wall over the ovarian fat pad, which was gently pulled out to expose oviduct, ovary, and the upper part of uterus. Up to eight embryos were transferred into each uterine horn with a fine glass pipette. Each uterus was then returned to the body cavity, and the skin incision closed with Michel clips as previously described. Embryos in different treatment groups were transferred into different female recipient mice. All the recipients were allowed to deliver and raise pups. Live born pups were either raised to weaning age to check their normality or mated with their siblings from the same litter for fertility testing.

\section{Histological examination}

Fresh and cryopreserved-thawed ovarian grafts were fixed in Bouin's fixative overnight, dehydrated manually through a graded ethanol series, and embedded in paraffin. Five micron $(5 \mu \mathrm{m})$ serial sections were stained with hematoxylin and eosin and examined under an Olympus CX41 upright microscope.

\section{Statistical analysis}

Graft recovery and survival and number of pups born within and between treatment groups were compared using a $\chi^{2}$ test. The result of oocyte collected per quarter-ovarian grafts was presented as mean \pm S.E.M. and analyzed by one-way ANOVA. The data of oocyte maturation, cleavage and blastocyst rate in each oocyte classification of the different treatment groups were expressed as mean \pm S.E.M. and analyzed by multivariate ANOVA. $P<0.05$ was considered to be a significant difference. SPSS 12.0.1. (SPSS Inc., Chicago, IL, USA) was used for all statistical analyses.

\section{Declaration of interest}

We declare that there is no conflict of interest that can perceived as prejudicing the impartiality of our research.

\section{Funding}

This research did not receive any specific grant from any funding agency in the public, commercial or not-for-profit sector. 


\section{Acknowledgements}

Authors thank Dr Kais Hamza from School of Mathematical Science at Monash University for statistical analyses, Dr Jillian Shaw from the Melbourne School of Land and Environment, University of Melbourne for helpful discussions, and Dr Sarah Jansen for statistical support and valuable manuscript preparation. We acknowledge Susan Chapman for performing embryo transfer procedures and Ji Min Ham for technical assistance.

\section{References}

Aerts JM, De Clercq JB, Andries S, Leroy JL, Van Aelst S \& Bols PE 2008 Follicle survival and growth to antral stages in short-term murine ovarian cortical transplants after cryologic solid surface vitrification or slow-rate freezing. Cryobiology 57 163-169.

Al-aghbari AM \& Menino AR 2002 Survival of oocytes recovered from vitrified sheep ovarian tissues. Animal Reproduction Science $\mathbf{7 1}$ 101-110.

Almodin CG, Minguetti-Camara VC, Meister H, Ferreira JO, Franco RL, Cavalcante AA, Radaelli MR, Bahls AS, Moron AF \& Murta CG 2004 Recovery of fertility after grafting of cryopreserved germinative tissue in female rabbits following radiotherapy. Human Reproduction 19 1287-1293.

Amorim CA, Goncalves PB \& Figueiredo JR 2003 Cryopreservation of oocytes from pre-antral follicles. Human Reproduction Update $\mathbf{9}$ 119-129.

Anderiesz C \& Trounson AO 1995 The effect of testosterone on the maturation and developmental capacity of murine oocytes in vitro. Human Reproduction 10 2377-2381.

Andersen CY, Rosendahl M, Byskov AG, Loft A, Ottosen C, Dueholm M, Schmidt KL, Andersen AN \& Ernst E 2008 Two successful pregnancies following autotransplantation of frozen/thawed ovarian tissue. Human Reproduction 23 2266-2272.

Aubard Y, Newton H, Scheffer G \& Gosden R 1998 Conservation of the follicular population in irradiated rats by the cryopreservation and orthotopic autografting of ovarian tissue. European Journal of Obstetrics, Gynecology, and Reproductive Biology 79 83-87.

Bath LE, Wallace WH \& Critchley HO 2002 Late effects of the treatment of childhood cancer on the female reproductive system and the potential for fertility preservation. British Journal of Obstetrics and Gynaecology 109 107-114.

Beebe L, Mcllifatrick S, Ashman R \& Nottle M 2006 In vitro survival of porcine blastocysts vitrified using the cryologic vitrification method. Reproduction, Fertility, and Development 18149.

Bosch P, Hernandez-Fonseca HJ, Miller DM, Wininger JD, Massey JB, Lamb SV \& Brackett BG 2004 Development of antral follicles in cryopreserved cat ovarian tissue transplanted to immunodeficient mice. Theriogenology 61 581-594.

Candy CJ, Wood MJ \& Whittingham DG 1995 Follicular development in cryopreserved marmoset ovarian tissue after transplantation. Human Reproduction 10 2334-2338.

Candy CJ, Wood MJ \& Whittingham DG 2000 Restoration of a normal reproductive lifespan after grafting of cryopreserved mouse ovaries. Human Reproduction 15 1300-1304.

Chang HC, Liu H, Zhang J, Grifo J \& Krey LC 2005 Developmental incompetency of denuded mouse oocytes undergoing maturation in vitro is ooplasmic in nature and is associated with aberrant Oct-4 expression. Human Reproduction 20 1958-1968.

Chen SU, Chien CL, Wu MY, Chen TH, Lai SM, Lin CW \& Yang YS 2006 Novel direct cover vitrification for cryopreservation of ovarian tissues increases follicle viability and pregnancy capability in mice. Human Reproduction 21 2794-2800.

Chen GA, Cai XY, Lian Y, Zheng XY, Qiao J, Chen XN \& Ye RH 2008 Normal birth from cryopreserved embryos after intracytoplasmic sperm injection of frozen semen into vitrified human oocytes. Human Fertility 11 49-51.
Chian RC, Niwa K \& Sirard MA 1994 Effects of cumulus cells on male pronuclear formation and subsequent early development of bovine oocytes in vitro. Theriogenology 41 1499-1508.

Chin AH \& Chye NS 2004 Investigations of oocyte in vitro maturation within a mouse model. Zygote 12 1-18.

Cortvrindt R, Smitz J \& Van Steirteghem AC 1996 In vitro maturation, fertilization and embryo development of immature oocytes from early preantral follicles from prepuberal mice in a simplified culture system. Human Reproduction 11 2656-2666.

Costigan S, Henman M \& Stojanov T 2006 Non-immersion vitrification - a viable alternative to slow freezing of blastocysts. Fertility and Sterility $\mathbf{8 6}$ S208.

Cox SL, Shaw J \& Jenkin G 2000 Follicular development in transplanted fetal and neonatal mouse ovaries is influenced by the gonadal status of the adult recipient. Fertility and Sterility 74 366-371.

Dandekar PV, Martin MC \& Glass RH 1991 Maturation of immature oocytes by coculture with granulosa cells. Fertility and Sterility $\mathbf{5 5}$ 95-99.

Demeestere I, Simon P, Emiliani S, Delbaere A \& Englert Y 2007 Fertility preservation: successful transplantation of cryopreserved ovarian tissue in a young patient previously treated for Hodgkin's disease. Oncologist 12 1437-1442.

Demirci B, Lornage J, Salle B, Poirel MT, Guerin JF \& Franck M 2003 The cryopreservation of ovarian tissue: uses and indications in veterinary medicine. Theriogenology 60 999-1010.

Donnez J, Dolmans MM, Demylle D, Jadoul P, Pirard C, Squifflet J, Martinez-Madrid B \& Van Langendonckt A 2004 Livebirth after orthotopic transplantation of cryopreserved ovarian tissue. Lancet 364 $1405-1410$.

Donnez J, Martinez-Madrid B, Jadoul P, Van Langendonckt A, Demylle D \& Dolmans MM 2006 Ovarian tissue cryopreservation and transplantation: a review. Human Reproduction Update 12 519-535.

Fraser LR 1984 Mouse sperm capacitation in vitro involves loss of a surfaceassociated inhibitory component. Journal of Reproduction and Fertility 72 373-384.

Fry R, Earl C, Fry K \& Lindemans W 2005 Pregnancy rates in the field after the transfer of bovine IVP embryos vitrified by the cryologic vitrification method. Reproduction, Fertility, and Development 17272.

Gilchrist RB, Ritter LJ \& Armstrong DT 2004 Oocyte-somatic cell interactions during follicle development in mammals. Animal Reproduction Science 82-83 431-446.

Gosden RG, Mullan J, Picton HM, Yin H \& Tan SL 2002 Current perspective on primordial follicle cryopreservation and culture for reproductive medicine. Human Reproduction Update 8 105-110.

Goud PT, Goud AP, Qian C, Laverge H, Van der Elst J, De Sutter P \& Dhont M 1998 In vitro maturation of human germinal vesicle stage oocytes: role of cumulus cells and epidermal growth factor in the culture medium. Human Reproduction 13 1638-1644.

Johnson JE, Higdon HL III \& Boone WR 2008 Effect of human granulosa cell co-culture using standard culture media on the maturation and fertilization potential of immature human oocytes. Fertility and Sterility 90 1674-1679.

Kagawa N, Kuwayama M, Nakata K, Vajta G, Silber S, Manabe N \& Kato O 2007 Production of the first offspring from oocytes derived from fresh and cryopreserved pre-antral follicles of adult mice. Reproductive Biomedicine Online 14 693-699.

Kim SS, Soules MR \& Battaglia DE 2002 Follicular development, ovulation, and corpus luteum formation in cryopreserved human ovarian tissue after xenotransplantation. Fertility and Sterility 78 77-82.

Kito S \& Bavister B 1997 Gonadotropins, serum, and amino acids alter nuclear maturation, cumulus expansion, and oocyte morphology in hamster cumulus-oocyte complexes in vitro. Biology of Reproduction 56 1281-1289.

Lane M, Bavister B, Lyons E \& Forest K 1999 Containerless vitrification of mammalian oocytes and embryos. Nature Biotechnology 17 1234-1236.

Lee RK, Ho HY, Yu SL \& Lu CH 2005 Blastocyst development after cryopreservation and subcutaneous transplantation of mouse ovarian tissues. Journal of Assisted Reproduction and Genetics 22 95-101.

Levi Setti PE, Albani E, Novara PV, Cesana A, Bianchi S \& Negri L 2005 Normal birth after transfer of cryopreserved human embryos generated by microinjection of cryopreserved testicular spermatozoa into cryopreserved human oocytes. Fertility and Sterility 831041. 
Li YB, Zhou CQ, Yang GF, Wang Q \& Dong Y 2007 Modified vitrification method for cryopreservation of human ovarian tissues. Chinese Medical Journal 120 110-114.

Liu J, Van der Elst J, Van den Broecke R \& Dhont M 2001 Live offspring by in vitro fertilization of oocytes from cryopreserved primordial mouse follicles after sequential in vivo transplantation and in vitro maturation. Biology of Reproduction 64 171-178.

Martino A, Songsasen N \& Leibo SP 1996 Development into blastocysts of bovine oocytes cryopreserved by ultra-rapid cooling. Biology of Reproduction 54 1059-1069.

Meirow D, Levron J, Eldar-Geva T, Hardan I, Fridman E, Zalel Y, Schiff E \& Dor J 2005 Pregnancy after transplantation of cryopreserved ovarian tissue in a patient with ovarian failure after chemotherapy. New England Journal of Medicine 353 318-321.

Ménézo YJR 2004 Blastocyst freezing. European Journal of Obstetrics, Gynecology, and Reproductive Biology 115 S12-S15.

Moor RM, Dai Y, Lee C \& Fulka JJ 1998 Oocyte maturation and embryonic failure. Human Reproduction Update 4 223-226.

Nagy A, Gersenstein M, Vintersten K \& Behringer R 2003 Manipulating the Mouse Embryo: A Laboratory Manual, edn 3. New York: Cold Spring Harbour Laboratory Press.

Papis K, Shimizu M \& Izaike Y 2000 Factors affecting the survivability of bovine oocytes vitrified in droplets. Theriogenology 54 651-658.

Salle B, Demirci B, Franck M, Berthollet C \& Lornage J 2003 Long-term follow-up of cryopreserved hemi-ovary autografts in ewes: pregnancies, births, and histologic assessment. Fertility and Sterility $80172-177$.

Santos RR, Tharasanit T, Van Haeften T, Figueiredo JR, Silva JR \& Van den Hurk R 2007 Vitrification of goat preantral follicles enclosed in ovarian tissue by using conventional and solid-surface vitrification methods. Cell and Tissue Research 327 167-176.

Snow M, Cox SL, Jenkin G, Trounson A \& Shaw J 2002 Generation of live young from xenografted mouse ovaries. Science 2972227.

Snow M, Cox SL, Jenkin G \& Shaw J 2004 Fertility of mice following receipt of ovaries slow cooled in dimethyl sulphoxide or ethylene glycol is largely independent of cryopreservation equilibration time and temperature. Reproduction, Fertility, and Development 15 407-414.
Summers MC, Bhatnagar PR, Lawitts JA \& Biggers JD 1995 Fertilization in vitro of mouse ova from inbred and outbred strains: complete preimplantation embryo development in glucose-supplemented KSOM. Biology of Reproduction 53 431-437.

Tao Y, Cao C, Zhang M, Fang F, Liu Y, Zhang Y, Ding J \& Zhang X 2008 Effects of cumulus cells on rabbit oocyte in vitro maturation. Journal of Animal Physiology and Animal Nutrition 92 438-447.

Vajta G, Holm P, Kuwayama M, Booth PJ, Jacobsen H, Greve T \& Callesen H 1998 Open pulled straw (OPS) vitrification: a new way to reduce cryoinjuries of bovine ova and embryos. Molecular Reproduction and Development 51 53-58.

Wolvekamp MC, Cleary ML, Cox SL, Shaw JM, Jenkin G \& Trounson AO 2001 Follicular development in cryopreserved common Wombat ovarian tissue xenografted to Nude rats. Animal Reproduction Science 65 135-147.

Wongsrikeao P, Kaneshige Y, Ooki R, Taniguchi M, Agung B, Nii M \& Otoi T 2005 Effect of the removal of cumulus cells on the nuclear maturation, fertilization and development of porcine oocytes. Reproduction in Domestic Animals 40 166-170.

Yamazaki Y, Wakayama T \& Yanagimachi R 2001 Contribution of cumulus cells and serum to the maturation of oocyte cytoplasm as revealed by intracytoplasmic sperm injection (ICSI). Zygote 9 277-282.

Yeoman RR, Wolf DP \& Lee DM 2005 Coculture of monkey ovarian tissue increases survival after vitrification and slow-rate freezing. Fertility and Sterility 83 1248-1254.

Youssry M, Ozmen B, Zohni K, Diedrich K \& Al-Hasani S 2008 Current aspects of blastocyst cryopreservation. Reproductive Biomedicine Online 16 311-320.

Received 20 April 2009

First decision 5 June 2009

Accepted 25 June 2009 